\title{
Factors Affecting Short Term Outcome in Isolated Congenital Diaphragmatic Hernia: A Cohort Study from A Tertiary Surgical Center
}

\author{
Seyyed Javad Nasiri ${ }^{1}$ \\ Maryam Ghavami Adel ${ }^{1 *}$ \\ Mohammad Reza Keramati ${ }^{2}$
}

'Department of Pediatric Surgery Iran University of Medical Sciences Tehran, Iran.

${ }^{2}$ Assistant Professor of Surgery Tehran University of Medical Sciences Tehran, Iran.

*Correspondence to:

Dr. Maryam Ghavami Adel Assistant Professor

Department of Pediatric Surgery Keshyarz Blvd, Imam Hospital

Tehran University of Medical Science Tehran, Iran.

Mobile +989123258250

Email: mghadel@yahoo.ca

www.banglajol.info/index.php/CMOSHMCJ

\begin{abstract}
Background: The mortality rate of Congenital Diaphragmatic Hernia (CDH) is still high in many centers. Most important factors influencing the outcome are pulmonary hypoplasia and associated anomalies. In this study, postnatal factors affecting short term outcome of patients with isolated $\mathrm{CDH}$ will be studied in an educational children hospital. Methods : This is a historical cohort study, on newborns with isolated posterolateral congenital diaphragmatic hernia from 2005 to 2015. Relative risks of variables for the short term outcome (Discharged alive or expired) were calculated. We also analyzed the highest $\mathrm{PaO}_{2}$, which was measured during the course of the management in the patients. Location of the liver and stomach were detected, too. Results: Fifty-three patients were studied, including 28(52.8\%) male and 25(47.2\%) female. Mean Gestational Age (GA) was 38 weeks (Range: 33-40) and mean body weight was 3001.22 (Range: 1300 - 4200) grams. Forty-two (79.2\%) presented with left sided hernia, and 10(18.9\%) had right sided defect. Thirty-two (60.4\%) patients discharged alive, and 21(39.6\%) expired. Mortality rate for right sided hernias was $70 \%(7 / 10)$, and for left sided ones was $31 \%(13 / 42)$. Sex, weight, GA, stomach and liver herniation had no significant effect on survival. Side of involvement, time of presentation (Onset of symptoms), first measured $\mathrm{PaO}_{2}$, and first measured $\mathrm{PaCO}_{2}$, had significant influences on survival. Conclusion: According to our analysis, side of hernia, time of onset of symptoms, and initial $\mathrm{PaO}_{2}$ and $\mathrm{PaCO}_{2}$ are factors predicting survival in children with congenital diaphragmatic hernia. Although, we may predict the early outcome of the patients, more studies are needed in this regard.
\end{abstract}

Key words: Congenital; Diaphragmatic hernia; Survival.

\section{INTRODUCTION}

The mortality rate of Congenital Diaphragmatic Hernia (CDH) is still high in many centers $^{1}$. Most important factors influencing the outcome are pulmonary hypoplasia and associated anomalies. In the absence of associated anomalies, prediction of the degree of hypoplasia and the risk factors could be a guide for better management. There are a group of studies performed on predicting the mortality rate of the disease. Some of these studies are based on evaluating factors during fetal life and the others are based on measuring factors immediately after birth. In these patients, hypoplasia of the ipsilateral and contralateral lungs results in pulmonary hypertension and eventually left ventricle dysfunction. So, the main step in the management of these patients is to control pulmonary hypertension. According to the studies, multiple factors which have effect on survival are detected such as APGAR score, LHR (lung to head ratio), first $\mathrm{PH}$, first $\mathrm{PaCO}_{2}$, liver herniation, lung volume, and lung perfusion ${ }^{2-8}$. Using ECMO (Extracorporeal Membrane Oxygenation), the survival of these patients improved very much. High cost and inaccessibility are its main problems in developing countries. 
In this study it is tried to detect some of the postnatal factors which affect the short term outcome of patients with isolated congenital diaphragmatic hernia in an educational children hospital. Finding these factors will help physicians and surgeons in better management of these patients to reach a better survival rate.

\section{METHODS AND MATERIALS}

In this historical cohort study, newborns with the diagnosis of isolated posterolateral congenital diaphragmatic hernia admitted from 2005 to 2015 were studied. The study has been approved by the ethics committee of Tehran University of Medical Sciences.

Exclusion criteria were congenital heart anomalies which were detected clinically or by echocardiogram, and any other anomalies which could affect the survival. In all of the patients, sex, birth weight, Gestational Age (GA), first time of presentation, laterality (Side of involvement), first $\mathrm{PaO}_{2}$, first $\mathrm{PaCO}_{2}$, pulmonary hypertension, liver and stomach anatomic location were also recorded.

Relative risks of these variables for the short term outcome (Discharged alive or expired) were calculated. We also analyzed the highest $\mathrm{PaO}_{2}$, which was measured during the course of the management of the patients. Location of the liver and stomach were detected by ultrasonography, chest X-ray, and during operation in those who were operated. Our strategy for surgery was delay surgery (After physiologic stabilization of the patient).

Statistical analysis was done using Statistical Package for Social Sciences (SPSS) software version 16.

\section{RESULTS}

In this study, a total of 53 patients were studied, including $28(52.8 \%)$ male and 25(47.2\%) female. Mean gestational age was 38 weeks (Range: 33-40) and mean body weight was 3001.22 (Range: 1300 - 4200) grams. Forty-two (79.2\%) patients presented with left sided hernia, $10(18.9 \%)$ with right sided defect, and $1(1.9 \%)$ with bilateral involvement. Thirtyseven $(69.8 \%)$ underwent surgical management and in 16 $(30.2 \%)$ surgery could not be accomplished. Thirty-two (60.4\%) patients discharged alive, and 21 (39.6\%) cases expired before or after surgical treatment. Mortality for right sided hernias was $70 \%(7 / 10)$, and for the left sided ones was $31 \%(13 / 42)$.

Sex, weight, GA, stomach and liver herniation had no significant effect on survival. Side of involvement, time of presentation(onset of symptoms), first $\mathrm{PaO}_{2}$, and first $\mathrm{PaCO}_{2}$, had significant influences on survival. Right side involvement had more than two times Relative Risk (RR) for mortality compared with the left side. Relative Risk (RR) of the first $\mathrm{PaO}_{2}=<60$ was 3.00 [(CI 95\%; $\left.\left.1.307-6.886\right) \mathrm{p}=.002\right]$. The patients with first $\mathrm{PaCO}_{2}=<60$ had 2.54 times more chance for survival, [(CI 95\%; 1.07-6.16) $\mathrm{p}=.006]$. The patients with the onset of clinical presentation less than 6 hours had 10.9 RR for mortality in comparison with the patients who had onset after 6 hours, [(CI 95\%; 1.59-74.74) $\mathrm{p}=.000]$. Among the patients who expired, 63.2\% (12/19) had been experienced the $\mathrm{PaO}_{2}$ more than $96 \mathrm{mhg}$ during the course of their management.

\section{DISCUSSION}

In many centers $\mathrm{CDH}$ has a high mortality. There are two main factors affecting mortality in these patients including associated anomalies and degree of lung hypoplasia ${ }^{1}$. In isolated congenital diaphragmatic hernia, it seems that there should be a significant association between degree of the lung hypoplasia and pulmonary hypertension (Persistent fetal circulation), which is the main factor affecting the survival. In recent years, some studies have been done to predict the prognosis of these patients and to improve the survival. For survival analysis, different types of data have been used including anatomic data and physiologic data. Anatomic data such as lung volume, LHR, liver position, side of involvement and in one study sonographic findings showing liver herniation and lung size can increase the accuracy of predicting mortality in these patients 9 . Most of these anatomic data are evaluated during fetal life but physiologic data are usually evaluated immediately or shortly after birth. Timely evaluation of the anatomic data during fetal life, could be a guide for termination or preservation the fetus or a guide for providing and programming the type of management after delivery.

According to a study by Gien $\mathrm{J}$ et al as the pathophysiology of pulmonary hypertension changes in the days and weeks after birth, its management must be specialized ${ }^{10}$. The physiologic data could only be a guide for type of management and consulting the parent about the chance and rate of success. In this study all the patients were evaluated after birth by checking some of the physiologic and anatomic data. All the patients were managed by conventional ventilation with a mortality rate of nearly $40 \%$. First $\mathrm{PaO}_{2}$, first $\mathrm{PaCO}_{2}$, time of presentation and side of involvement were the factors which had significant relative risk for survival in our cases.

In another study, the mortality rate had been $50 \%$, they also used conventional ventilation ${ }^{11}$. In another study, they observed no significant survival benefit for high-frequency jet ventilation, $8.0 \%$ (95 confidence interval, $-22.0 \%$ to $38.1 \%, \mathrm{P}=$ $.59)^{12}$. In our study we noticed that $63 \%$ of the expired patients had $\mathrm{PaO}_{2}>90$, during the course of their management by conventional ventilation. Therefore, it could be an alarm that we still need more information about the behavior of the hypoplastic lung and the ventilator setting.

In many centers there are some promises in improvement of survival by applying ECMO, but it is associated with some complication $^{13}$. On the other hand, it is not available easily in many centers. According to Kalanj $\mathrm{J}$ et al, by further increase of prenatal diagnosis, planning for delivery, and coordinated transfer to tertiary centers, we can prevent the hazardous of transferring these fragile patients ${ }^{14}$. As we mentioned previously because of its cost and inaccessibility we may have to find some other accessible solutions. 


\section{CONCLUSION}

Congenital diaphragmatic hernia management is challenging. Early diagnosis and correction the predicting factors may increase the survival. According to our analysis, side of hernia, time of onset of symptoms, and initial $\mathrm{PaO}_{2}$ and $\mathrm{PaCO}_{2}$ are factors predicting survival in children with congenital diaphragmatic hernia. Although, we may predict the early outcome of the patients, more studies are needed in this regard.
Considering ventilator modalities, concentrating on prenatal early diagnosis, equipping the nursing care unit and planning for delivery in tertiary center can increase the survival. Further investigations about the behavior of the hypoplastic lungs and pulmonary hypertension management are required.

\section{DISCLOSURE}

All the authors declared no competing interest.

\section{REFERENCES}

1. Chao PH, Huang CB, Liu CA, Chung MY, Chen CC, Chen FS, Ou-Yang MC, Huang HC. Congenital diaphragmatic hernia in the neonatal period: Review of 21 years' experience.Pediatr Neonatol. 2010; 51(2):97-102.

2. Mullassery D, Ba'ath ME, Jesudason EC, Losty HYPERLINK "http://www.ncbi.nlm.nih.gov/pubmed/20178116" Value of liver herniation in prediction of outcome in fetal congenital diaphragmatic hernia: A systematic review and meta-analysis.PDUtrasound Obstet Gynecol. 2010;35(5):609-614.

3. Hoffman SB, Massaro AN, Gingalewski C, Short BL. Predictors of survival in congenital diaphragmatic hernia patients requiring extracorporeal membrane oxygenation: CNMC 15-year experience.J Perinatol. 2010 Aug;30(8):546-552. Epub 2010 Feb 11.

4. Kilian AK, Büsing KA, Schuetz EM, Schaible T, Neff KWFetal MR lung volumetry in Congenital Diaphragmatic Hernia (CDH): Prediction of clinical outcome and the need for Extracorporeal Membrane Oxygenation (ECMO). Klin Padiatr. 2009;221(5):295-301. Epub 2009 Aug 25.

5. Nishie A, Tajima T, Asayama Y, Ishigami K, Hirakawa M, Nakayama T, Ushijima Y, Kakihara D, Okamoto D, Yoshiura T, Masumoto K, Taguchi T, Tsukimori K, Tokunaga S, Irie H, Yoshimitsu K, Honda H .MR prediction of postnatal outcomes in left-sided congenital diaphragmatic hernia using right lung signal intensity: Comparison with that using right lung volume.J Magn Reson Imaging. 2009;30(1):112-120.

6. Cruz-Martínez R, Moreno-Alvarez O, Hernández-Andrade E, Castanon M, Martínez JM, Done E, Deprest J, Gratacós E.Changes in Lung Tissue Perfusion in the Prediction of Survival in Fetuses with Congenital Diaphragmatic Hernia Treated with Fetal Endoscopic Tracheal Occlusion.Fetal Diagn Ther. 2010. [Epub ahead of print].

7. Ruano R, Aubry MC, Barthe B, Dumez Y, Benachi A.Three-dimensional ultrasonographic measurements of the fetal lungs for prediction of perinatal outcome in isolated congenital diaphragmatic hernia.J Obstet Gynaecol Res. 2009;35(6):1031-1041.

8. Knox E, Lissauer D, Khan K, Kilby M. Prenatal detection of pulmonary hypoplasia in fetuses with congenital diaphragmatic hernia: A systematic review and meta-analysis of diagnostic studies.J Matern Fetal Neonatal Med. 2010;23(7):579-588.

9. Sananes N, Britto I, Akinkuotu AC, Olutoye OO, Cass DL, Sangi-Haghpeykar H, Lee TC, Cassady CI, Mehollin-Ray A, Welty S, Fernandes C,Belfort MA, Lee W, Ruano R Improving the Prediction of Neonatal Outcomes in Isolated Left-Sided Congenital Diaphragmatic Hernia by Direct and Indirect Sonographic Assessment of Liver Herniation.J Ultrasound Med. 2016. pii: 15.07020. [Epub ahead of print].

10. Gien J, Kinsella JP. Management of pulmonary hypertension in infants with congenital diaphragmatic hernia .J Perinatol. 2016;36 Suppl 2:S28-31. doi: $10.1038 / \mathrm{jp} .2016 .46$.

11. Ozdogan T, Durakbasa C, Mutus M, Iscen M. Congenital diaphragmatic hernia: A 4-year experience in a single centre.Afr J Paediatr Surg. 2010;7(2):105-106.

12. Kuluz MA, Smith PB, Mears SP, Benjamin JR, Tracy ET, Williford WL, Goldberg RN, Rice HE, Cotten CM.Preliminary observations of the use of high-frequency jet ventilation as rescue therapy in infants with congenital diaphragmatic hernia.J Pediatr Surg. 2010;45(4):698-702.

13. Kattan J, Godoy L, Zavala A, Faunes M, Becker P, Estay A, Fabres J, Toso P, Urzúa S, Becker J, Cerda J, González A.Improvement of survival in infants with congenital diaphragmatic hernia in recent years: Effect of ECMO availability and associated factors.Pediatr Surg Int.2010;26(7):671676. Epub 2010 May 29.

14. Kalanj J, Salevic P, Rsovac S, Medjo B, Antunovic SS, Simic D. Congenital diaphragmatic hernia : A Belgrade single center experience. J Perinat Med. 2016. pii: /j/jpme.ahead-of-print/jpm-2015-0333/jpm-2015-0333.xml. doi: 10.1515/jpm-2015-0333. [Epub ahead of print]. 